\title{
trabalhonecessário
}

issn: $1808-799 x$

ano 8 - número 11 - 2010

\section{TRABALHO, ARTE E EDUCAÇÃO. ESTADO DA ARTE DA PESQUISA E O TRABALHO DO PESQUISADOR}

\begin{abstract}
Ronaldo Rosas Reis ${ }^{1}$
RESUMO

NOTAS

O texto expõe o estado da arte da pesquisa sobre as relações sociais de produção artística e o ensino de arte no Brasil observando seus principais avanços em quatro anos. Tem por objetivos relatar e divulgar o desenvolvimento teórico-metodológico da pesquisa e refletir politicamente sobre o trabalho do pesquisador.

Palavras-chave: trabalho; arte-educação; política.
\end{abstract}

\section{ABSTRACT}

This paper presents the state of the art of research on the social relations of artistic production and teaching of art in Brazil watching its main achievements in four years. It aims to report and disclose the theoretical development and methodological research and to reflect politically on the researcher's work.

Keywords: work; art education; policy.

\section{APRESENTAÇÃO}

Faz parte da tradição da literatura da área de Arte-Educação voltar-se para temas relacionados com as questões metodológico-cognitivas e/ou com 0 universo das problemáticas centradas na didática e na prática pedagógica fortemente apoiada na empiria (estudos de caso) e ainda com a formação do arteeducador. A título de ilustração, das vinte e oito comunicações apresentadas no então Grupo de Estudo Educação e Arte na 30aㅡ Reunião Anual da ANPEd, em 2008, vinte e cinco delas seguiam essas linhas, duas traziam abordagens de natureza filosófica e/ou estética, e apenas uma se apresentava como de extração histórico-sociológica².

Longe de constituir uma observação crítica a uma limitação epistemológica da tradição mencionada, a constatação acima pretende situar nesse quadro a temática e o corte epistemológico e metodológico da pesquisa "Trabalho, arte e educação no Brasil. As relações sociais de produção artística e o ensino de arte" que realizamos na Universidade Federal Fluminense com o auxílio do CNPq. Para

\footnotetext{
${ }^{1}$ Doutor em Comunicação e Cultura (UFRJ, 1994). Professor da Faculdade de Educação da Universidade Federal Fluminense. Pesquisador do CNPq.ronaldo.rosas@globo.com

${ }^{2}$ Trata-se do trabalho da professora Rose Meri Trojan, da Universidade Federal do Paraná. Cabe informar que naquela mesma Reunião Anual a Assembléia da ANPEd aprovaria a transformação do referido GE em Grupo de Trabalho em Educação e Arte (GTEA-24).
} 
além disso a observação indica os elementos de natureza ideológica nas esferas política e cultural, concomitantemente perseguidos no curso de pouco mais de três décadas de estudos sobre a produção de arte e do seu ensino no Brasil, incorporando ao todo cinco pesquisas concluídas e a atual em plena realização ${ }^{3}$.

A propósito desse tempo aparentemente exagerado, num trabalho recém publicado buscamos esclarecer sua relação com a trajetória acadêmica do tema de estudo reportando-se ao acúmulo das décadas de estudos mencionadas ${ }^{4}$. De outra forma, não seria por acaso que o tempo estendido/trajetória da pesquisa se insere, dentre outras preocupações, num contexto de disputa política atualíssima cuja relevância ganha cada vez mais um contorno ideológico-classista. Isto é, por um lado, face à necessidade urgente de os docentes-pesquisadores da área de arte-educação ampliar o espectro epistemológico e metodológico de suas investigações buscando superar a razão dualista (OLIVEIRA, 2003) que tem impregnado a práxis educacional ${ }^{5}$. Por outro lado, face à necessidade não menos urgente de os professores-pesquisadores resistirem à obsessão produtivista de parte significativa de seus pares que nas Instituições Federais de Ensino, muito especialmente nos Programas de Pós-Graduação, têm advogado favoravelmente à ideologia do mercado e, por intermédio das agências de fomento (CAPES, CNPq e FAPs), submetido a todos os docentes "critérios esdrúxulos, tais como, por exemplo, a pontuação para publicações no exterior em prestigiadas revistas científicas" (OLIVEIRA, 2009). Estudado de forma ampla e cuidadosa por João dos Reis e Valdemar Sguissardi (2009), o tema da intensificação/alienação do professor-pesquisador será aqui priorizado numa nota que busca expressar de forma complementar uma posição política face ao quadro atual das relações de produção de conhecimento na universidade.

\footnotetext{
3 A saber, pela ordem cronológica de realização: Ideologia e estética. Brasil construtos ideológicos. A arte brasileira nos anos 1950, realizada entre 1978 e 1981 (UFRJ/IFCS - CAPES); Ideologia versus estética. Silêncio e evidência na arte brasileira nos anos 1980 , realizada entre 1990 e 1994 (UFRJ/ECO); Globalização, pós-modernismo e dilemas da educação estética no Brasil, realizada entre 2000 e 2001 (UFMG/FAE - CAPES); Pós-modernismo, globalização e a formação estético-cultural do trabalhador urbano no Rio de Janeiro. Trajetórias, posições e embates no campo simbólico, realizada entre 2003 e 2007 (UFF/FAE - CNPq); Trabalho, arte e educação no Brasil. As relações sociais de produção artística e o ensino de arte, realizada entre 2007 e 2010 (UFF/FAE - CNPq). No momento (2010-2013) desenvolvemos a segunda etapa desta última pesquisa relacionada.

${ }^{4}$ Ver REIS (2010).

${ }^{5}$ Idem.
} 
O texto está organizado em três seções. Na seção 1, o Estado da Arte, encontram-se os dados gerais da pesquisa sobressaindo-se o contexto formador e uma síntese da memória descritiva e crítica dos passos dados no período 20072010. Nas seções 2 e 3, respectivamente, duas notas críticas abordam os temas esboçados logo acima nessa apresentação, compondo, conclusivamente, o quadro crítico-reflexivo do trabalho.

\section{ESTADO DA ARTE}

\subsection{Proposta Pedagógica}

A pesquisa "Trabalho, arte e educação no Brasil. As relações sociais de produção artística e o ensino de arte" tem sua base no Departamento Sociedade, Educação e Conhecimento e no Programa de Pós-Graduação da Faculdade de Educação da Universidade Federal Fluminense. Conta com uma bolsa de produtividade, uma bolsa de Iniciação Científica e com recursos oriundos do Edital Universal, todos do CNPq . Em 2007-2008 contou com o auxílio financeiro da FAPERJ. Sua etapa inicial teve início em março de 2007 e foi concluída em fevereiro de 2010, e sua etapa atual teve início em março de 2010 e deverá ser concluída em fevereiro de 2013.

Ao longo da primeira etapa o projeto agregou seis monografias de conclusão de curso de alunas do curso de Pedagogia, um trabalho de conclusão de curso de aluna do curso de História, cinco teses de doutorado e uma pesquisa de pós-doutorado 7 . Na etapa atual estão agregados seis monografias de conclusão de curso, uma pesquisa de doutorado e uma de mestrado com defesas previstas para 2010, 2011 e $2012^{8}$.

Os indicadores relativos à participação e produção de cada um no Grupo de Pesquisa no período 2007-2010 dão conta de um trabalho realizado cuja prioridade foi considerar cada passo dado, isto é, cada monografia, tese, artigo e comunicação apresentada em evento científico de acordo com uma visão de

\footnotetext{
${ }^{6}$ A bolsa de IC faz parte do PIBIC-UFF/CNPq (Programa Institucional de Bolsas de Iniciação Científica). O projeto foi contemplado nos períodos 2007-2008, 2008-2009 e 2009-2010, não tendo sido reapresentado para o atual período. O apoio do Edital Universal contempla o período 20092010.

${ }^{7}$ Trata-se da pesquisa 0 Processo Histórico de Criação da Casa dos Educandos Artífices em Manaus (1856-1877): Refletindo sobre os Caminhos da Educação Profissional, do Prof. Dr. Jorge Gregório da Silva da Faculdade de Educação da Universidade Federal do Amazonas, concluída em junho de 2010.

${ }^{8}$ Para início em 2011 foram abertas duas vagas de orientação na Pós-Graduação (mestrado e doutorado), com conclusões previstas para, respectivamente, 2013 e 2015.
} 
longo prazo tendo em vista ainda "o pressuposto marxiano de que toda mudança ocorre por transformações de caráter qualitativo" (ARGUELHO et al, 2006, p.4) ${ }^{9}$. Mais adiante a questão do longo prazo será retomada.

Cabe considerar que o propósito do método organizativo se baseou, fundamentalmente, no exercício da idéia que articula o ensino, a pesquisa e a extensão numa totalidade a ser apreendida e transformada, isso significando um processo de trabalho integrado no qual os resultados alcançados nas aulas, na produção decorrente das investigações científicas e nos debates dos ciclos de leitura e estudos de extensão se complementam, indicando a partir daí novos rumos e objetivos a serem perseguidos. Do ponto de vista prático é necessário chamar a atenção especialmente para o fato de que a oportunidade de reunir numa mesma equipe alunos da graduação de diferentes cursos, como pedagogia, jornalismo, cinema e história, alunos da pós-graduação em educação e professores em estágio pós-doutoral, tornou mais enriquecedora a formação acadêmica de todos eles, além de ter proporcionado a cada um dos participantes uma visão geral do seu papel e dos demais na produção científica do grupo de pesquisa.

\subsection{DIRETRIZES GERAIS}

O tema da investigação compreende a relação entre trabalho, arte e educação no Brasil, sendo o seu objeto as relações sociais de produção artística e a arte na educação. Duas problemáticas centrais afins com o objeto de estudo são consideradas no corpus analítico: o desenvolvimento cultural brasileiro sob o modo de produção capitalista e a luta de classes no Brasil. O objetivo geral da pesquisa é apreender, sistematizar e problematizar historicamente as relações sociais de produção de arte no país. Em outras palavras o que se pretende é apreender a totalidade dessas relações, procurando compreender quando e sob que condições gerais e específicas elas entram em contradição com as forças produtivas na dinâmica do desenvolvimento capitalista no Brasil. Especificamente a pesquisa quer analisar as condições históricas objetivas do trabalho artístico, como o material e a técnica utilizados, as mediações estéticas, o valor da produção, o mercado, a formação profissional e a escolaridade do artista plástico,

\footnotetext{
${ }^{9}$ Para uma visão completa da pesquisa e dos indicadores ver REIS, R. R. Relatório Científico. Brasília: CNPq, 2010. Disponível em www.uff.br/neddate.
} 
e ainda, o ensino de arte vinculado ao currículo escolar obrigatório da educação básica (níveis de ensino fundamental e médio).

\subsection{Periodização}

A abrangência historiográfica da pesquisa situa inicialmente o ano de 1816 - com a chegada ao Brasil da Missão Artística Francesa - e finalmente o ano de 1996 - com a promulgação dos Parâmetros Curriculares Nacionais de Arte, divididos em dois grandes períodos de estudos (1816-1951 e 1952-1996), e cada um deles subdivididos em dois períodos intermediários (1816-1921, 1922-1951, 1952-1981 e 1982-1996) totalizando quatro períodos a serem examinados em cada etapa. Veja-se no Quadro 1 a periodização da pesquisa de acordo com as etapas de realização:

\begin{tabular}{|c|c|c|c|}
\hline \multicolumn{2}{|c|}{ MARCOS } \\
\hline Etapa & Período & Tema de estudo & Desenvolvimento \\
\hline \multirow{2}{*}{$1^{\mathrm{a}}}$. & $1816-1921$ & Academicismo & $03 / 2007-02 / 2010$ \\
& $1922-1951$ & Modernismo & Concluída \\
\hline \multirow{2}{*}{$2^{\mathrm{a}}}$. & $1952-1981$ & Construtivismo & $03 / 2010-02 / 2013$ \\
& $1982-1996$ & Pós-modernismo & Em curso \\
\cline { 2 - 3 } & &
\end{tabular}

Com base no acúmulo do conhecimento resultante de pesquisas anteriores, a periodização foi organizada metodologicamente a partir de temas de estudo nos quais foram observados a produção do conhecimento socialmente referenciado em cada época, a saber: a linguagem artística; a ideologia estética, o télos educacional classista e as políticas culturais e educacionais. É importante sublinhar que o modelo cronológico sequencial tal como o apresentado no Quadro 2 não subordinou, necessariamente, o trabalho de levantamento e análise de dados à ordem apresentada. Pois, como foi dito logo acima, foi tomado como base para a sua organização metodológica períodos/temas demarcados já anteriormente investigados. Dessa forma, após uma revisão cuidadosa os dados coletados anteriormente $^{10}$ foram atualizados e incorporados aos corpus da pesquisa juntamente com os demais dados coletados e analisados em momento recente. Para tanto, ao mesmo tempo em que foram realizados ciclo de estudos e debates em torno do método baseado na economia política e da teoria estética de corte marxista para apreensão das categorias de análise da realidade, a equipe dedicou-se ao trabalho de levantamento dos dados essenciais para a composição

\footnotetext{
10 São os casos dos períodos/temas relativos ao "Construtivismo" (1952-1981) e "Pósmodernismo" (1982-1996).
} 
do quadro de referência dos períodos ainda carentes de informações. Nesse sentido, conforme será detalhado mais adiante, o ano de 2008 foi tanto dedicado ao levantamento de registros documentais (textuais e iconográficos) sobre o período inaugural da proposta de investigação (1816-1921), como igualmente à produção de textos sobre a produção e o ensino de arte em períodos já investigados.

Entre 2007 e 2009, sempre no primeiro semestre, a fim de estudar os temas pertinentes à investigação os orientandos participantes do Grupo de Pesquisa se organizaram em torno de três atividades acadêmicas: 1) a disciplina "Tópicos Especiais em Trabalho e Educação: Economia política e cultura", vinculada ao Programa de Pós-Graduação em Educação; 2) um seminário de orientação denominado "Ciclo de Leituras sobre Estética e Arte Brasileira"; 3) a disciplina "Tópicos especiais de Trabalho-Educação: Trabalho, arte e educação no Brasil" também vinculada ao Programa de Pós-Graduação em Educação. Nelas foram estudados e debatidos alguns conceitos fundamentais do pensamento marxiano, como ideologia, alienação, trabalho produtivo e improdutivo à luz de temas atuais relacionados com a estética e a produção artística brasileira mais recente. Além das evidentes conquistas teóricometodológicas a atividade foi importante para amalgamar o Grupo para a execução da proposta central e dos respectivos projetos de pesquisa individuais ${ }^{11}$.

\subsection{Novos ELEMENTOS CONCEITUAIS}

A extraordinária quantidade de documentos textuais e iconográficos foi coletado e fotografado em instituições como o Arquivo Nacional, Biblioteca Nacional, Museu Nacional de Belas-Artes, Museu de Arte Moderna do Rio de Janeiro e de São Paulo, Museu de Arte de São Paulo etc. permitiram ao longo do processo de trabalho a produção de quatro conjuntos de reflexões críticas em fase organização para uma publicação integrada, possivelmente em dois volumes. No tocante aos períodos relativos à primeira etapa, a pesquisa concentrou-se em documentos emitidos pela Coroa, pela nobreza portuguesa recém chegada ao Brasil e pela burguesia brasileira relacionada com, dentre outras coisas, a implantação da Escola Real de Belas Artes, a importação de bens artísticos, a compra e a venda desses bens, notas de pagamento para

\footnotetext{
${ }^{11}$ Cabe ressaltar que as atividades atraíram o interesse de professores de outros cursos da UFF e mestrandos de outros Programas, como o de História da UFF.
} 
serviços de instrução artística e afins. Ainda na primeira etapa relativamente ao período compreendido entre 1922 e 1951, procedeu-se ao levantamento e estudo de fontes documentais sobre as escolas e liceus de artes e ofícios e aos ateliês formados por filhos de emigrantes operários, bem como ao acúmulo de bens culturais por parte das frações burguesas ligadas às ideologias desenvolvimentistas. Grande parte desse material empírico já processado foi utilizado em artigos e comunicações em eventos científicos ${ }^{12}$.

Quanto ao horizonte epistemológico alcançado pela pesquisa, deve-se observar o seguinte quadro de conceitos-chave:

1. O caráter determinista das ideologias estéticas no ajustamento teleológico da arte moderna ao Sistema de Belas-Artes;

2. O caráter absenteísta da maioria dos estudos sobre a arte o seu ensino no Brasil quanto a sua materialidade histórica, conferindo a ambos a idéia de algo destituído do trabalho humano e das relações sociais daí decorrentes;

3. O fato de que longe de constituir uma prioridade para a formação estéticocultural da sociedade, a arte no Brasil visa constituir força de trabalho excedente num quadro histórico onde acumulação primitiva (informalidade) tem prevalecido sobre o mercado formal de bens artísticos ${ }^{13}$.

\section{SOBRE ARTE, ENSINO DE ARTE E REESTRUTURAÇÃO PRODUTIVA}

A partir dos resultados dos estudos realizados, considerando especificamente o papel do ensino regular de artes e ofícios no que diz respeito ao tema da reestruturação produtiva do país no século XIX e de suas conseqüências na esfera ideológica em meio a qual observamos ao aparecimento dos primeiros traços da razão dualista que nos persegue até hoje, pode-se afirmar a importância estratégica central da Academia Imperial de Belas-Artes e de seus sucedâneos (na linha da própria academia e dos liceus) no processo de reestruturação da economia brasileira a médio e longo prazo. Seja abrindo espaço para o aparecimento de manufaturas industriais mediante a formação de mão de obra especializada, seja para a criação de um Sistema de Belas-Artes mediante a formação de artistas para atender à demanda estético-cultural de uma fração nova da burguesia, urbana e voltada para o empresariamento industrial.

De fato, dentre outros propósitos subordinados, se à Academia cabia levar adiante o plano estratégico de produzir conhecimento, estabelecer um método científico de trabalho e uma hierarquia disciplinar capaz de reproduzir os

\footnotetext{
${ }^{12}$ Ver REIS $(2008,2007)$.

${ }^{13}$ Cf. REIS (2008).
} 
ensinamentos ministrados, e, no limite, instaurar um aparato legislador das coisas da arte com vistas à formação de um Sistema de Belas-Artes que correspondesse aos objetivos hegemônicos da classe dominante, aos liceus e outras escolas de ofícios cabia tarefa semelhante ajustada ao nível da classe trabalhadora. Não obstante, a ignorância ou descaso que as elites de um modo geral devotavam pela herança artística colonial, o desprezo que sentiam pelo trabalho manual era ainda maior, o que tornaria a tarefa de sistematizar a produção artística ainda mais complexa. Contudo, isso se fez de duas maneiras complementares. Isto é, por um lado, a Academia construiria junto às elites do país a idéia de que a produção artística acadêmica interessava estrategicamente ao Estado, seja como forma de acumulação de um capital simbólico à altura dos seus dirigentes e, por conseguinte das elites, seja como forma de reprodução do capital acumulado ${ }^{14}$. Por outro lado, construindo imaginariamente a tradição das Belas-Artes no país, seja universalizando a idéia de uma hierarquização fundada em princípios éticos e estéticos insuspeitos porquanto baseada no domínio competente da técnica, seja apagando ou mascarando oficialmente os resquícios da tradição colonial.

Dessa forma, dada a sua centralidade estratégica, o ensino de artes e ofícios, respectivamente, tornar-se-iam teleologicamente determinantes na indicação do caminho a ser percorrido pela sociedade brasileira na busca do progresso nacional. À precisão da técnica, ao conhecimento científico dos materiais e ao domínio das ferramentas, apanágios do lluminismo, associava-se o pensamento positivista a considerar a ordem como sinônimo de modernização. Nascia, assim, no seio das elites da época, um discurso paradigmático fundado num tipo de razão dualista a alinhar, de um lado, modernização e riqueza e, de outro lado, conservadorismo e pobreza.

\section{OTRABALHO DO PESQUISADOR: OLONGO PRAZO COMOIDEOLOGIADARESISTÊNCIA}

Em 2006, este periódico publicou um extraordinário artigo das professoras Ana Arguelho, Elcia de Arruda, Sonia Maria Pereira e Maria de Fátima E. M. Lima

\footnotetext{
${ }^{14}$ Para BARBOSA (1978), a República teria agido preconceituosamente contra "[...] o dirigismo característico do espírito neoclássico de que estava impregnada (a Academia)", posto que esta estivera à serviço da conservação do poder do Império (1978, p.16). Ao nosso ver a posição da autora, apoiada tão somente em fatos, carece de consistência teórico-metodológica quando não examina a totalidade das relações socioculturais no contexto da revolução burguesa no Brasil. Talvez, por esse mesmo motivo, no seu texto, ela se insista na idéia simplista de "preconceito" ao dizer que ao substituir "o calor do emocionalismo barroco da arte colonial pela frieza do intelectualismo da estética neoclássica, [esta última] teria encontrado eco apenas na pequena burguesia"(Idem, pp.18-19).
} 
acerca do método de pesquisa. No texto as professoras expunham com clareza meridiana uma concepção de pesquisa às avessas do pragmatismo e do empirismo (ainda e cada vez mais) dominantes e explicitavam a diferença entre o empírico e o concreto, categorias fundantes de métodos de pesquisa radicalmente opostos. Nesse sentido, chamavam atenção para o fato de que a materialidade de um objeto de estudo deve, necessariamente,

"[...] conter em si elementos universais e, portanto, não observáveis, impossíveis de serem apreendidos, senão por meio da teoria. Não de qualquer teoria, mas daquelas que permitem a compreensão da historicidade do objeto, teorias que ao serem formuladas conseguiram apreender o movimento do conjunto dos homens na produção da vida, suas contradições, seus embates, ao longo dos tempos" (2006, p.3)

A despeito da atualidade do tema proposto pelas professoras, hoje parece restar muito pouco do tempo em que a disputa ideológica por posições teóricometodológicas centralizava e dinamizava as relações de produção do conhecimento na universidade. O trabalho de formar pessoas, alimentar a cultura, produzir e fazer avançar o conhecimento científico a partir de posições as quais se creditava a substância política daquelas relações parece ter sido colocado num plano secundário. A lembrança de um texto sobre o método de pesquisa aqui se faz então, e, sobretudo, pelo contraponto que ele traz ao estado atual das relações sociais de produção na universidade, no qual se observa por parte significativa dos docentes-pesquisadores o abandono da arena daquela disputa e a entrega obsessiva e acrítica ao produtivismo, conforme foi mencionado na apresentação do presente trabalho.

Em suas incontáveis variáveis, a obsessão produtivista se impõe pela demanda insaciável de artigos-mercadorias comprimindo o tempo do docentepesquisador. Nessa condição específica o docente é explorado à exaustão passando a exercer tarefas prescritas pela exigência de mais artigos-mercadoria, exigência a qual ele sublima mediante um processo denominado de "evangelização da mercadoria" (ESQUEF, 2009). Isto é, o poder fetichista da mercadoria assume uma positividade doutrinária aprofundando o processo de reificação ou coisificação das relações sociais de produção. Cabe observar com Richard Sennett que o "tempo é o único recurso que os que estão no fundo da sociedade têm de graça" (2002, p.14), e que, portanto, se apreendido numa perspectiva classista, força-nos a pensar o "longo prazo" como uma posição ideológica e uma estratégia política de resistência. Do ponto de vista da 
coletividade o tempo estendido traz a vantagem de obrigar o pesquisador a reconhecer sistematicamente os limites de cada descoberta feita no momento de sua inserção histórica, levando-o permanentemente a pensar a "sua" pesquisa como uma práxis socialmente referenciada. Do ponto de vista da singularidade de cada um, o "longo prazo" permite que se verifique se a permanência de determinados dilemas é real ou se é fruto de alguma neurose obsessiva comum a todos os pesquisadores exigentes ${ }^{15}$.

\section{REFERÊNCIAS BIBLIOGRÁFICAS}

ARGUELHO, A. et al. "Sobre (o) viver das crianças e adolescentes: uma reflexão sobre o método de pesquisa". In Trabalho Necessário ano $4, n^{\circ} 4$. Niterói: UFF/Neddate, $\quad 2006, \quad$ pp. 1-14. Disponível em http://www.uff.br/trabalhonecessario/TN4\%20ARGUELHO\%20SOUZA, \%20A.\% 20et\%20al.pdf.

BARBOSA, Ana Mae. Arte e educação no Brasil. São Paulo: Perspectiva, 1978.

MACIEL, Marcos Antonio Esquef. Desenho industrial e desenvolvimentismo. As relações sociais de produção e o ensino do design no Brasil. Niterói: UFF/Programa de Pós-Graduação em Educação, Tese de Doutorado, mimeog. 2009.

OLIVEIRA, F. "Recuperando a visão". In SILVA JR., J. R.; SGUISSARDI, V. Trabalho intensificado nas federais. Pós-graduação e produtivismo acadêmico. São Paulo, SP: Xamã, Prefácio, 2009, pp. 11-25.

REIS, Ronaldo Rosas. "Trabalho, arte e educação no Brasil. Sobre a dualidade no Ensino de Arte". In CIAVATTA, M.; REIS, R. R. (Org.) A pesquisa histórica em trabalho e educação. Manaus/Brasília: EDUA/Líber, 2010, pp. 65-87.

"Do cérebro para os olhos. Trabalho de arte, classe e educação". In Anais da 31a Reunião Anual da Associação Nacional de Pesquisa e Pós-Graduação. Caxambu: ANPEd, 2008, pp. 1-15. Disponível em http://www.anped.org.br/reunioes/31 ra/1trabalho/GT09-4225--Int.pdf

"A dimensão ético-estética da relação trabalho e educação". In Trabalho Necessário n 5 . Niterói: UFF/Neddate, 2007, pp. 1 20. Disponível em http://www.uff.br/trabalhonecessario/TN5\%20REIS,\%20R.R..pdf.

SARTRE, Jean-Paul. As palavras. Rio de Janeiro, RJ: Difel, 1978.

SENNETT, Richard. A corrosão do caráter. Consequências pessoais do trabalho no novo capitalismo. Rio de Janeiro, RJ: Record, 2002.

SILVA JR., J. R.; SGUISSARDI, V. Trabalho intensificado nas federais. Pósgraduação e produtivismo acadêmico. São Paulo, SP: Xamã, Prefácio, 2009.

TROJAN, Rose Meri. "(Pós) modernismo, trabalho e educação". In Anais da 30a Reunião Anual da Associação Nacional de Pesquisa e Pós-Graduação em

\footnotetext{
${ }^{15}$ Parafraseando Sartre (1978), escrever é desfazer-se de uma neurose sem que isso represente a cura de si próprio.
} 
Educação, ANPEd. Caxambu, MG: ANPEd, 2008. Disponível em www.anped.org.br/reunioes/30ra/grupo estudos/GE01-3018--Int.pdf. 